\title{
Original
}

\section{Fibrous Calcareous Concretions in the Capsules of Human Pineal Glands}

\author{
Tetsuo KodaKA ${ }^{1)}$, Ryoichi Mori ${ }^{2)}$, Hiromitsu Ezure ${ }^{2)}$, \\ Junji Iто $^{3)}$ and Naruhito OтsuKA ${ }^{2)}$
}

\begin{abstract}
We examined calcareous concretions in the capsule of 15 human pineal glands containing a large amount of the concretions in the matrix. The capsule concretions, brown to blackish-brown in color and/or translucent, were smaller than the matrix concretions, which were yellowish-white. The matrix concretions showed the typical mulberry-shaped overall appearance with scallop-shaped concentric laminations of non-fibrous structures, but the capsule concretions, which also contained $\mathrm{Ca}$ and $\mathrm{P}$, showed a globular or oval shape with regular, rough, or no concentric laminations. The capsule concretions also showed globules of mineralized collagen fibers that resembled randomly wound threads and that were occasionally associated with minute spherical deposits showing hypermineralization in the core region as initial calcification. $\mathrm{Na}$ was detected as a minor characteristic element of the capsule concretions, and at a significantly higher level than that of the matrix concretions. The findings strongly suggested that a human pineal gland containing numerous matrix concretions is likely to produce mineralized deposits in the capsule.
\end{abstract}

Key words : human pineal capsule, fibrous concretions, minute spherical deposits, backscattered electron imaging, energy-dispersive X-ray microanalysis

\section{Introduction}

Non-fibrous calcareous concretions in the pineal matrix of some mammals ${ }^{1-3)}$ and humans ${ }^{2-11)}$ are formed by a fine lamination of alternating organic-rich and mineral-rich materials ${ }^{1,11)}$. These matrix concretions, known also as psammoma bodies or brain sands, show a mulberry-shaped overall appearance $^{4,6,10)}$ with the characteristic scallop-shaped laminations ${ }^{1,3,8,10,11)}$. Many of the matrix concretions may initially start at the calcified pinealocytes or other cells ${ }^{1,3,8,11)}$.

The characteristic structure of calcareous concretions was also observed in the connective tissue capsule of the pineal gland in aging rats by transmission electron microscopy ${ }^{12}$. However, such structures or their components remain to be identified in humans, although the presence of concretions in the pineal capsule was reportedly observed by optical microscopy ${ }^{5,8}$.

Previously ${ }^{13)}$, we reported pineal calcareous concretions and prostatic calculi in 40 deceased

\footnotetext{
1) Class of Anatomical-physiology, Musashigaoka College, 111-1 Minami-Yoshimi, Yoshimi-cho, Hiki-gun, Saitama 3550154, Japan.

2) Department of Anatomy, Showa University School of Medicine.

3) Department of Physical Therapeutics, Showa University School of Nursing and Rehabilitation Sciences.
} 
men ranging in age from 31 to 95 years. The coincident presence of these masses did not correlate with aging, but there tended to be a low negative correlation between their mineralized volumes assessed by microradiography. Human pineal glands containing a large number of matrix concretions also occasionally contain encapsulated masses ${ }^{8)}$, although these are smaller than the matrix concretions ${ }^{5,8)}$.

This study examined the capsule of adult human pineal glands ${ }^{13)}$ containing numerous matrix concretions by backscattered electron (BSE) imaging and energy-dispersive X-ray (EDX) microanalysis using a scanning electron microscope (SEM), and then by decalcified sections stained with van-Gieson, after observing the whole pineal glands by microradiography ${ }^{13)}$.

\section{Materials and Methods}

Human pineal glands were extracted from 40 deceased adult men (aged 51 to 85 years), who had agreed for their bodies to be employed for medical research, during the routine dissection course conducted from 1996 to 1998 at Showa University School of Dentistry ${ }^{13)}$. The tissues were, fixed in $10 \%$ neutral formalin and then stored in $70 \%$ ethanol. Radiographs showing the lateral view of the pineal glands were taken with a soft X-ray device (Sofron, Tokyo, Japan ${ }^{13)}$, and then 15 pineal glands containing a large amount of calcareous concretions in the matrix body were used.

Seven pineal glands were embedded in polyester resin after dehydration in ethanol. The samples were cut sagittally into several slices with a diamond wheel and then ground with grinding stones. Contact microradiographs of approximately $200-\mu \mathrm{m}$-thick slices were obtained, and the ground surfaces were polished with 5- and $0.3-\mu \mathrm{m}$ alumina on polishing cloths, and then ultrasonically cleaned. The sections were observed by transmitted-light microscopy (LM).

The ground surfaces were also observed by composite BSE imaging with an SEM (S-2500CX; Hitachi, Tokyo, Japan) operated at $20 \mathrm{keV}$ after carbon coating. Masses showing a high BSE signal in the pineal capsule and matrix regions were analyzed qualitatively and quantitatively by SEM equipped with an EDX detection system (delta-4; Kevex Instruments. Valencia, CA, USA), at an accelerating voltage of $15 \mathrm{keV}$, a specimen irradiation current of $1 \times 10^{-7} \mathrm{~mA}$, and a beam spot of $15 \mathrm{~nm}$. The central and peripheral regions in each mass showing high BSE signals were counted at 35 points (pineal regions) or 10 points (matrix regions) and their means ( \pm S.D.), were obtained.

Four samples out of the remaining resin-free pineal glands were sagittally cut into several slices with a diamond knife, dehydrated with ethanol, and then dried at the critical point of $\mathrm{CO}_{2}$. Conventional secondary scanning electron (SE) micrographs and composite BSE images of the cut surfaces of the ground pineal glands or the cut surfaces of pineal concretions themselves were photographed with an SEM operated at $15 \sim 20 \mathrm{keV}$ after carbon coating. The areas possessing higher molecular-weight elements in biological materials show higher BSE signals in the uneven planes of natural surfaces ${ }^{14)}$ and fractured surfaces ${ }^{15)}$, as well as the ground smooth planes $^{8,11)}$.

The remaining four samples were embedded in paraffin and 8 - $\mu$ m-thick sections were 

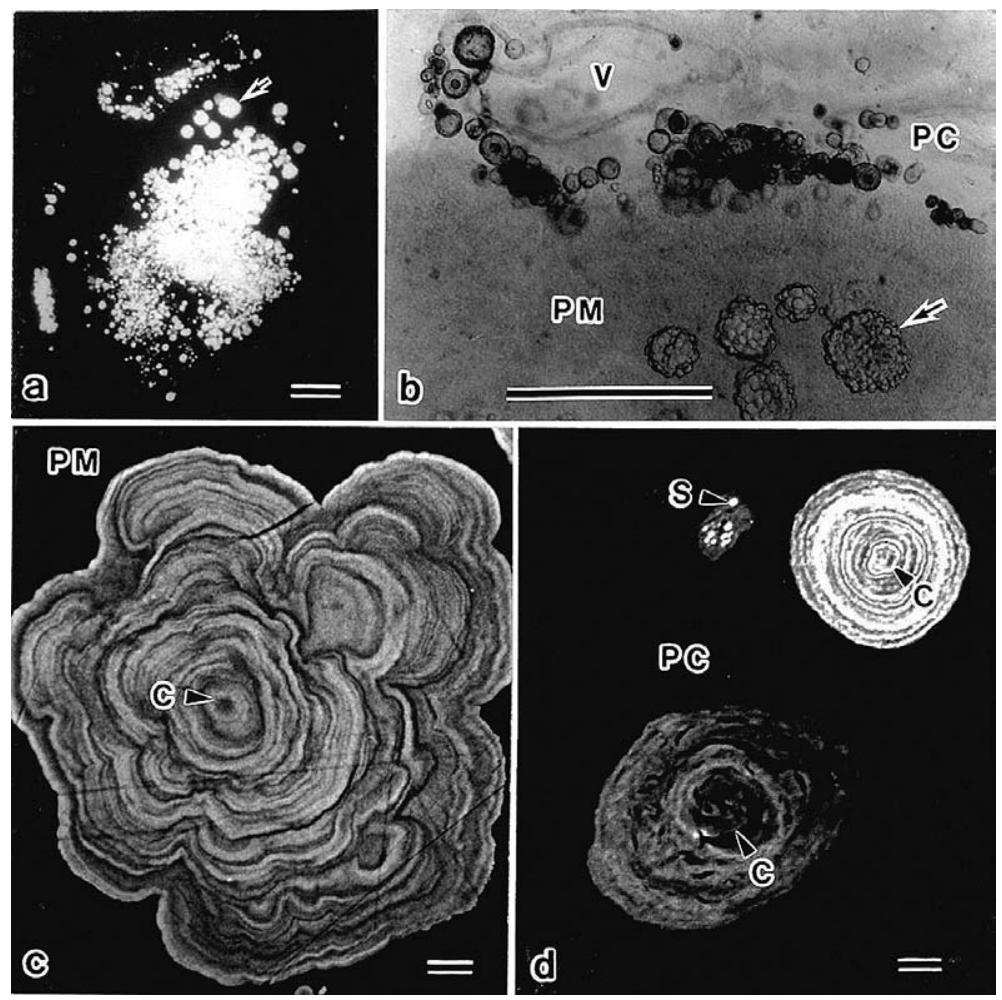

Fig. 1. Ground sections of human pineal glands embedded in resin. (a) Contact microradiograph, (b) ordinary light, and (c-g) BSE images. Arrows in (a) and (b) show the same matrix concretion. V, blood vessel. PC, pineal capsule. PM, pineal matrix. C, central or core region of a capsule or matrix concretion. S, minute spherical deposits (MSD) showing high BSE signal. (a, b) Bars, $1 \mathrm{~mm}$, (c, d) Bars, $100 \mu \mathrm{m}$.

prepared. The sections were stained with van-Gieson for the identification of collagen fibers, and were observed by LM.

\section{Results}

The ground sections of human pineal gland embedded in resin (Fig. 1a $\sim \mathrm{d}$ ) showed aggregations of radiopaque deposits in the pineal periphery as well as in the matrix body by contact microradiography (Fig. 1a). Figure 1b shows the LM photograph of part of Figure 1a. The calcareous concretions were apparent in the pineal capsule containing blood vessels as well as in the matrix. The matrix concretions were a yellowish-white color and usually showed a mulberry-like overall appearance by LM, whereas the center or whole area of the capsule concretions was occasionally brown to blackish-brown, and translucent in parts; these masses were basically circular in appearance and contained few or no concentric rings (Fig. 1b). They were also relatively smaller than the matrix concretions with a maximum diameter of up to $120 \mu \mathrm{m}$.

Fig. 1 (c, d) shows the composite BSE images of the capsule and matrix concretions in the ground surfaces of the resin-embedded pineal glands. The matrix concretions had scallop- 

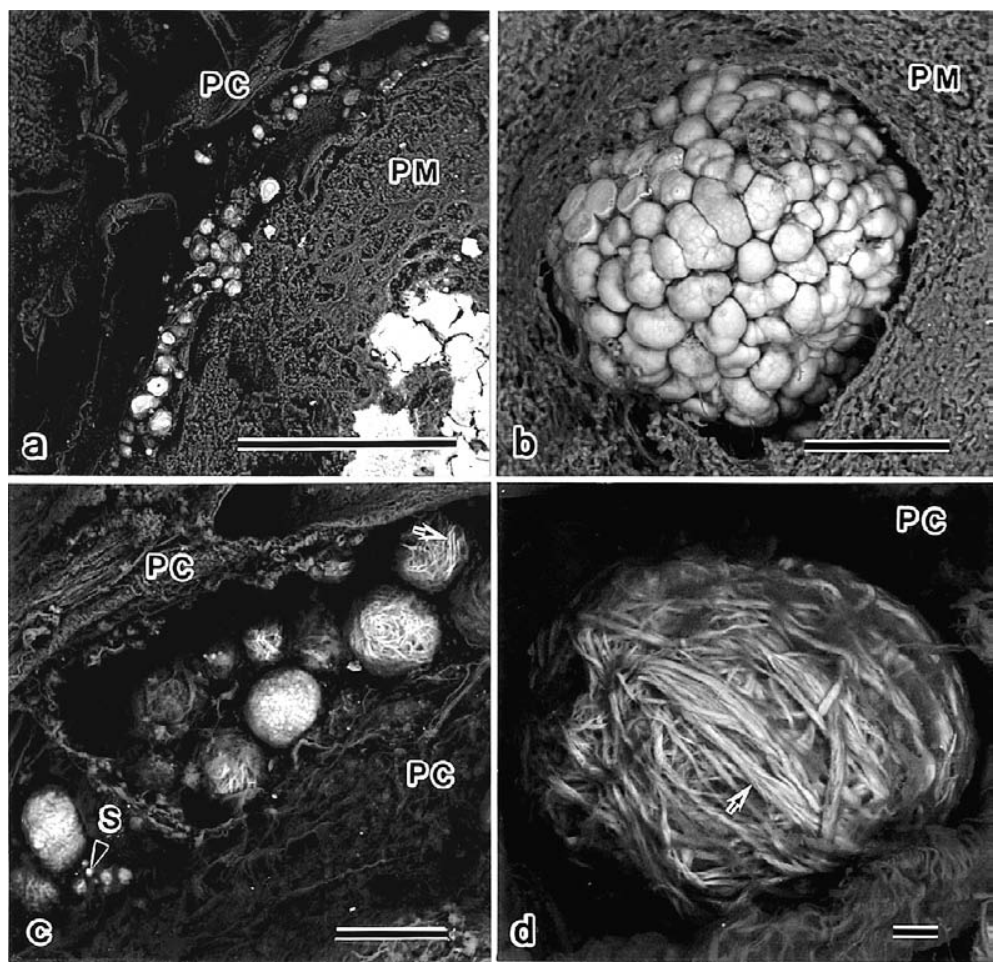

Fig. 2. BSE images of capsule and matrix concretions in the cut surfaces of resin-free pineal glands. PC, pineal capsule. PM, pineal matrix. The arrow indiccates fibrous structures with relatively high BSE signals. S, minute spherical deposits (MSD) showing high BSE signals. (a) Bar, $1 \mathrm{~mm}$, (b, c) Bars, $100 \mu \mathrm{m}$, (d) Bar $10 \mu \mathrm{m}$.

shaped concentric laminations (Fig. 1c), whereas the capsule concretions showed several different structural patterns even between neighboring concretions (Fig. 1d). Of the three capsule concretions visible in Fig. 1d, one large high-BSE-signal concretion showed almost regular concentric laminations around the core region, whereas the other lower-BSE-signal concretion showed roughly concentric laminations containing linear structures around the loose core region. The remaining smaller concretion had an oval-shaped outline and contained minute spherical deposits (MSD) showing higher BSE signals.

Fig. $2(\mathrm{a} \sim \mathrm{c})$ shows the BSE images of the cut surfaces of the resin-free pineal glands. The capsule concretions were clearly distinguishable from the matrix concretions in position and size (Fig. 2a). The matrix concretions usually showed a mulberry-shaped overall appearance in the three-dimensional image (Fig. 2b), whereas many of the capsule concretions were covered with fibrous structures showing high and low BSE signals. The overall appearance was a more or less globular structure that looked like randomly wound threads (Fig. 2c, d). Some of the initial mineralizing capsule concretions contained MSD that emitted high-BSE signals (Fig. 2c).

Fig. $3(\mathrm{a} \sim \mathrm{d})$ shows several capsule concretions that were initially mineralized at higher magnifications on the cut surfaces of a pineal capsule. Comparison of the overall appearance of a globular capsule concretion by SEM imaging (Fig. 3a) and composite BSE imaging of 


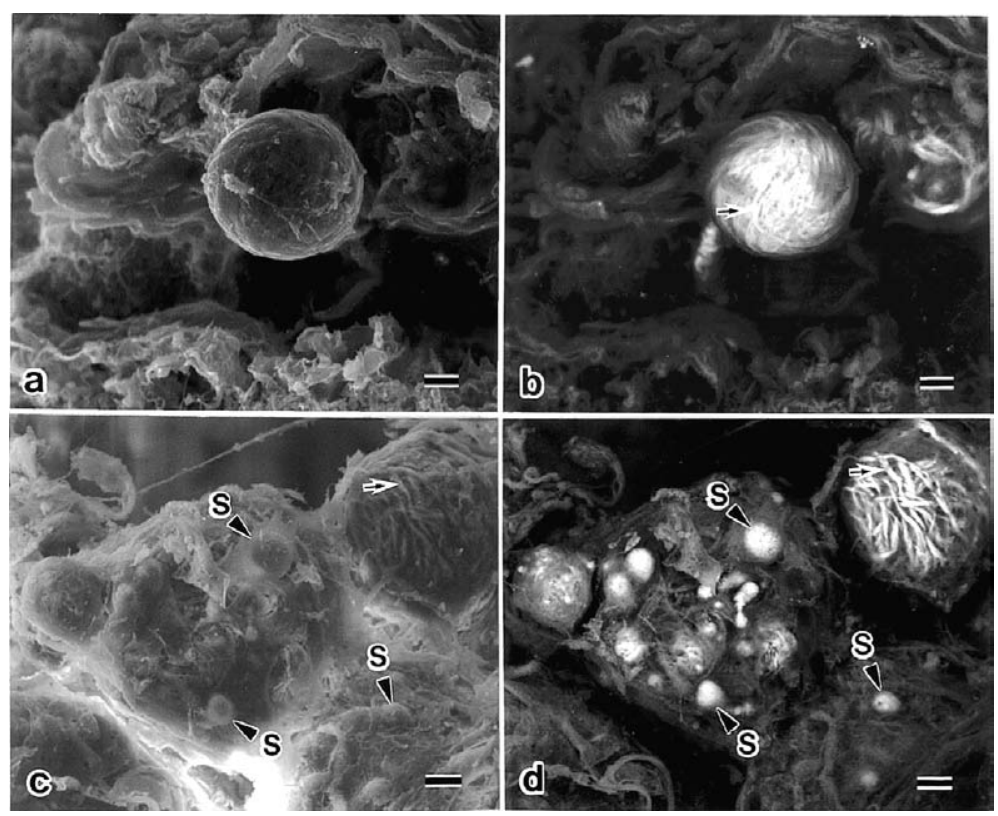

Fig. 3. SE micrographs (a, c) and BSE images (b, d) of initially mineralizing capsule concretions in the cut surfaces of resinfree pineal glands. (a, b) and (c, d) show the same regions, respectively. The arrow indicaes fibrous structures showing relatively high BSE signals. S, minute spherical deposits (MSD) showing high BSE signals. (a-d) Bars, $10 \mu \mathrm{m}$.
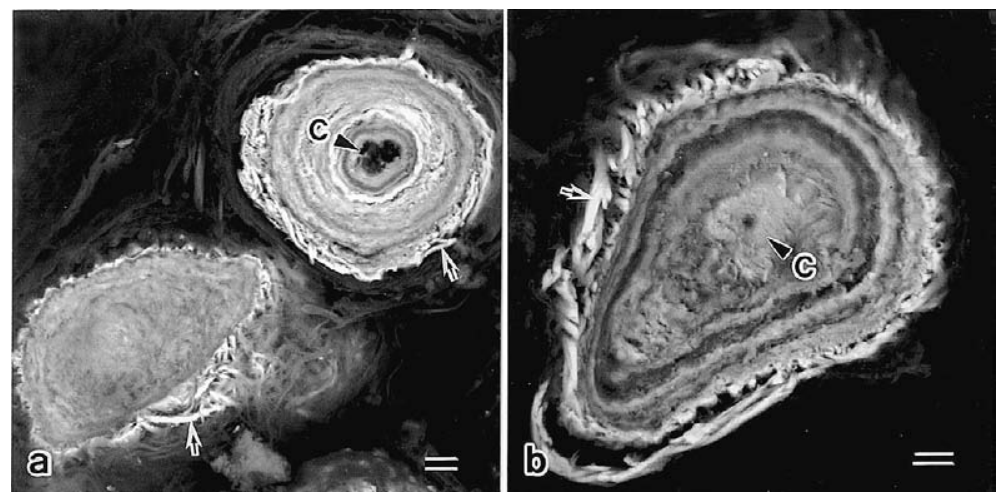

Fig. 4. Capsule concretions in the cut surfaces of resin-free pineal glands by BSE imaging. Arrows indicate fibrous structures showing high BSE signals. C, core region of a capsule concretion. (a, b) Bars, $10 \mu \mathrm{m}$.

the same field (Fig. 3b) showed the fibrous structures as randomly wound threads on the BSE image, whereas the same structures were undistinguishable in the SE micrograph. When the cut surfaces of globular capsule concretions were similarly compared, the fibrous structures and MSD showing high BSE signals could be also distinguished in an SE micrograph of the same field (Fig. 3c, d).

Fig. 4 (a, b) represents the cut surfaces of three larger capsule concretions showing high 


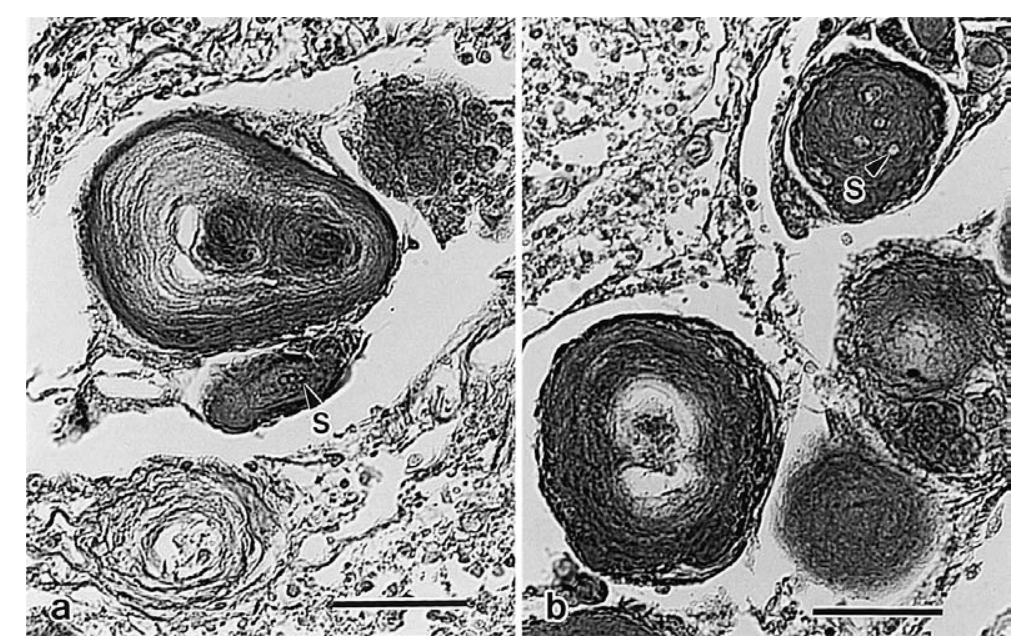

Fig. 5. LM photographs of the decalcified sections of pineal capsules stained with van-Gieson. S, minute spherical deposits (MSD) in the capsule concretions. (a, b) Bars, $50 \mu \mathrm{m}$.

BSE signals. The two oval-shaped concretions showed concentric laminations containing various linear structures around the core region showing low and higher BSE signals, respectively. The remaining globular capsule concretion comprised somewhat amorphous deposits containing linear structures in the core region. The peripheries of these three capsule concretions were surrounded with fibrous structures showing a high BSE signal.

Fig. 5 ( $\mathrm{a}, \mathrm{b}$ ) shows the decalcified sections stained with van-Gieson for identification of collagen fibers. Globular concretions in the pineal capsules were concentrically surrounded with collagen fibers, in an arrangement that resembled randomly wound threads, with MSD detected in the central region of some capsule concretions.

Under SEM-EDX microanalysis, $\mathrm{Ca}$ and $\mathrm{P}$ as major elements and $\mathrm{Na}$ as a minor element were detected in the capsule calcareous concretions and mineralized blood vessels showing high or lower BSE signals on the resin-embedded ground samples. As trace elements, $\mathrm{Mg}, \mathrm{S}, \mathrm{Cl}, \mathrm{K}$, $\mathrm{Al}$, and $\mathrm{Si}$ were detected. The concentrations of $\mathrm{Ca}, \mathrm{P}$, and $\mathrm{Na}$, and the $\mathrm{Ca} / \mathrm{P}$ molar ratio in the mineralized capsule deposits and matrix calcareous concretions were also then quantified (Table 1). These concretions ranged from 60 to $120 \mu \mathrm{m}$ in diameter based on BSE imaging. Under Student's $t$-test, the capsule concretions contained significantly lower $\mathrm{P}$ content than the matrix concretions in both the central $(P<0.01)$ and peripheral regions $(P<0.05)$, although the capsule concretions contained higher $\mathrm{Na}$ content $(P<0.001)$.

\section{Discussion}

In this study, the capsule concretions appeared mineralized in a contact microradiograph by $\mathrm{LM}^{8)}$ and the size was usually smaller than that of the matrix concretions ${ }^{3,8)}$, but the color has was not denoted. The color difference between these pineal concretions may be based on their rough or dense compositions of organic and mineral components. That is, the concretions showing a brown to blackish-brown color might be rich in organic components and the 
Table 1. Concentrations of $\mathrm{Ca}, \mathrm{P}$, and $\mathrm{Na}$ (weight \%), and the $\mathrm{Ca} / \mathrm{P}$ (molar ratio) in the capsule concretions $(n=35)$ and the matrix concretions with high BSE signals $(n=10)$ in human pineal gland. The concretions ranged between 60 and $120 \mu \mathrm{m}$ in diameter. SEM-EDX microanalysis was conducted in the center and periphery of the concretions.

\begin{tabular}{ccc}
\hline Capsule concretion & Center & Periphery \\
\hline $\mathrm{Ca}$ & $27.29 \pm 3.50$ & $26.32 \pm 2.88$ \\
$\mathrm{P}$ & $12.75 \pm 1.63^{\mathrm{a}}$ & $12.64 \pm 1.40^{\mathrm{b}}$ \\
$\mathrm{Na}$ & $1.98 \pm 0.69^{\mathrm{e}}$ & $1.96 \pm 0.07^{\mathrm{e}}$ \\
$\mathrm{Ca} / \mathrm{P}$ & $1.64 \pm 0.09$ & $1.62 \pm 0.04$ \\
\hline Matrix concretion & Center & Periphery \\
\hline $\mathrm{Ca}$ & $29.68 \pm 1.52$ & $28.57 \pm 1.87$ \\
$\mathrm{P}$ & $14.22 \pm 0.33^{\mathrm{c}}$ & $14.27 \pm 0.43^{\mathrm{d}}$ \\
$\mathrm{Na}$ & $0.11 \pm 0.02^{\mathrm{f}}$ & $0.11 \pm 0.03^{\mathrm{f}}$ \\
$\mathrm{Ca} / \mathrm{P}$ & $1.61 \pm 0.09^{\mathrm{g}}$ & $1.55 \pm 0.04^{\mathrm{h}}$ \\
\hline
\end{tabular}

Mean \pm S.D.

$\mathrm{Ca}, \mathrm{P}$, and $\mathrm{Na}$ : \% by weight; $\mathrm{Ca} / \mathrm{P}$ : molar ratio

a vs. c, $P<0.01$; b vs. d, $P<0.05$;

e vs. f, $P<0.001 ; \mathrm{g}$ vs. h, $P<0.05$

translucent-rich concretions might be more mineralized.

The pineal capsule concretions showing high to lower BSE signals were calcified with $\mathrm{Ca}$ and $\mathrm{P}$ as were the pineal matrix concretions in adult humans ${ }^{4-6,9,10)}$ and aging rats $^{3)}$, and the capsule concretions in aging rats ${ }^{12}$. From the $\mathrm{Ca} / \mathrm{P}$ molar ratios measured in this study (Table 1), the deposits showing high BSE signals may contain hydroxyapatite, as reported previously for matrix concretions $^{1,3,7)}$.

Our comparison of concretions revealed a significantly higher $\mathrm{P}$ content in the matrix concretions compared to the capsule concretions in both the central and peripheral regions, although there was no significant difference in $\mathrm{Ca}$ content. Thus, the capsule concretions tended to show a lower calcification than matrix concretions of a similar size.

The Na content in human matrix concretions has been reported as $1.1 \sim 3.6 \%{ }^{6)}, 0.41 \%^{7)}$, and approximately $0.5 \%{ }^{9)}$ by weight. In this SEM-EDX microanalysis, the $\mathrm{Na}$ content in the matrix concretions was approximately $0.11 \%$ by weight, which is significantly lower than the 1.75 $\sim 1.98 \% \mathrm{Na}$ content in the capsule concretions (Table 1). However, data reported for matrix concretions by Galliani et $a l^{6)}$ showed a higher $\mathrm{Na}$ content compared with previous studies ${ }^{6,9)}$ and our present data. According to Driessens ${ }^{16}$, $\mathrm{Na}$ ions are usually present in the intercellular and cerebrospinal fluids and in plasma $(140 \mu \mathrm{mol} / 1)$. Therefore, some $\mathrm{Na}$ ions in the capsule concretions might be contained in $\mathrm{Na}$ - and $\mathrm{CO}_{3}$-containing apatite ${ }^{17)}$. However, further investigations will be necessary to define the presence and nature of $\mathrm{Na}$ in the calcified deposits of human pineal capsule. 
The minute spherical deposits (MSD) showing hypermineralization in this study were occasionally observed in the core region of the capsule concretions. These deposits were similar to the hypermineralized minute globular deposits (MGD) scattered within previously reported mesenteric stone-like masses ${ }^{17)}$, which were mainly composed of variously calcified collagen fibers and amorphous calcium phosphate deposits containing apatite and Mg-containing whitlockite ${ }^{17)}$, and were proposed to be formed from amorphous calcium phosphate containing $\mathrm{Mg}^{17)}$. The hypermineralized MSD observed here might therefore be formed from calcium phosphate containing $\mathrm{Na}$ at a lower crystallization state.

The capsule concretions in aging rats ${ }^{12)}$ and several psammoma bodies in humans ${ }^{18-20)}$ consisted of calcified collagen fibrils ${ }^{12,18-21)}$ that would be expected to be followed by cell fragments or matrix vesicles showing an initial calcification ${ }^{17-19)}$. The capsule concretions showed various amounts of fibrous globular structures and may indeed reflect the calcification of cell remnants or matrix vesicles ${ }^{17,19-21)}$. Further, some such cell remnants might become the hypermineralized MSD.

Humbert et $a l^{12}$ ) examined capsule concretions in aging rats by transmission electron microscopy and divided the concretions into two types: a multilayered concretion surrounded by numerous collagen fibrils and an extracellular concretion with incorporated collagen fibrils. Their observations ${ }^{12)}$ basically agreed with our present findings, although the rat capsule concretions were very small in size and irregular in shape. Based on previous studies ${ }^{12,18-21)}$ and our vanGieson staining, the fibers of the capsule concretions showing a randomly wound thread-like structure were identified as collagen fibers.

Previously ${ }^{15)}$, we reported a tendency for a low negative correlation between the masses of studied pineal glands containing a large amount of calcareous concretions from adult human males with low numbers of prostatic calculi. Therefore, in a human pineal gland that is likely to be mineralized, the mineralization would be expected to occur in the connective tissue capsule $^{12,18-21)}$ as well as in the matrix ${ }^{17,19,21)}$. A larger amount of mineralized deposits in a pineal gland might be caused by longer hours of natural daylight and also by electric light, judging from the animal experimentations reported previously ${ }^{22-24)}$.

\section{Acknowledgements}

We are grateful to Dr. Tsuneyoshi Sano and Miss. Sachiyo Kenmotsu for their kind cooperation. We also acknowledge the 15 adult male persons who agreed to their organs being used in our examination following death.

\section{Conflict of interest}

The authors have declared no conflict of interest.

\section{References}

1) Mabie CP, Wallace BM. Optical, physical and chemical properties of pineal gland calcifications. Calcif Tissue Res. 1974;16:59-71.

2) Krstic R. A combined scanning and transmission electron microscopic study and electron probe microanalysis of human pineal acerveuli. Cell Tissue Res. 1976;174:129-137.

3) Allen DJ, Allen JS, Didio LJ, et al. Scanning electron microscopy and X-ray microanalysis of the human pineal 
body with emphasis on calcareous concretions. J Submicrosc Cytol. 1981;13:675-695.

4) Galliani I, Falcieri E, Giangaspero F, et al. A preliminary study of human pineal gland concretions: structural and chemical analysis. Boll Soc Ital Biol Sper. 1990;66:615-622.

5) Vigh-Teichmann I, Vigh B. Immunocytochemistry and calcium cytochemistry of the mammalian pineal organ: a comparison with retina and submammalian pineal organs. Microsc Res Tech. 1992;21:227-241.

6) Bocchi G, Valdre G. Physical, chemical, and mineralogical characterization of carbonate-hydroxyapatite concretions of human pineal gland. J Inorganic Biochem. 1993;49:209-220.

7) Kodaka T, Mori R, Debari K, et al. Scanning electron microscopy and electron probe microanalysis studies of human pineal concretions. J Electron Microsc. 1994;43:307-317.

8) Humbert W, Pevet P. Calcium concretions in the pineal gland of aged rats: an ultrastructural and microanalytical study of their biogenesis. Cell Tissue Res. 1995;279:565-573.

9) Nakamura KT, Nakahara H, Nakamura M, et al. Ultrastructure and X-ray microanalysis study of human pineal concretions. Ann Anat. 1995;177:413-419.

10) Schmid HA, Raykhtsaum G. Age-related differences in the structure of human pineal calcium deposits: results of transmission electron microscopy and mineralographic microanalysis. J Pineal Res. 1995;18:12-20.

11) Kodaka T, Sano T, Mori R. Scanning electron microscopy subsequent to a combined treatment of $\mathrm{NaOCl}$ and EDTA in some non-collagenous calcified matrixes. J Electron Microsc. 2000;49:195-202.

12) Humbert W, Cuisinier F, Vogel JC, et al. A possible role of collagen fibrils in the process of calcification observed in the capsule of the pineal gland in aging rat. Cell Tissue Res. 1997;288:435-439.

13) Mori R, Kodaka T, Sano T. Preliminary report on the correlations among pineal concretions, prostatic calculi and age in human adult males. Anat Sci Int. 2003;78:181-184.

14) Kodaka T, Hirayama A, Sano T, et al. Fine structure and mineral components of primary calculi in some human prostates. J Electron Microsc. 2008;57:133-141.

15) Kodaka T, Sano T, Nakagawa K, et al. Structural and analytical comparison of gallbladder stones collected from a single patient, studies of five cases. Med Electron Microsc. 2004;37:130-140.

16) Driessens FCM. Mineral aspect of dentistry. Basel: Karger; 1982. (Monographs in oral science; 10).

17) Kodaka T, Mori R, Hirayama A, et al. Fine structure and mineral components of fibrous stonelike masses obtained from the human mesenteries. Med Electron Microsc. 2003;36:272-280.

18) Johannessen JV, Sobrrinho-Simoes M. The origin and significance of thyroid psammoma bodies. Lab Invest. 1980;43:287-296.

19) Kubota T, Hirano A, Yamamoto S, et al. The fine structure of psammoma bodies in meningocytic whorls. $J$ Neurol Exp Med. 1984;43:37-44.

20) Kubota T, Sato K, Yamamoto S, et al. Ultrastructural study of the formation of psammoma bodies in fibroblastic meningioma. J Neurosurg. 1984;60:512-517.

21) Christoffersen J, Landis WJ. A contribution with review to the description of mineralization of bone and other calcified tissues. Anat Rec. 1991;230:435-450.

22) Reiter RJ. Pineal control of a seasonal reproductive rhythm in male golden hamsters exposed to natural daylight and temperature. Endocrinology. 1973;92:423-430.

23) Tamarkin L, Westrom WK, Goldman BD. Effect of melatonin on the reproductive system of male and female hamster, a diurnal rhythm in sensitivity to melatonin. Endocrinology. 1976;99:1534-1541.

24) Reither RJ. Interaction of photoperiod, pineal and seasonal reproduction as exemplified by findings in hamster. Prog Reprod Biol. 1978;4:169-190.

[Received March 7, 2013 : Accepted March 28, 2013] 